\title{
EFFECTS OF L-GLUTAMINE ON ACETYLSALYCYLIC ACID INDUCED GASTRIC LESIONS AND ACID BACK DIFFUSION IN DOGS
}

\author{
Chen Road HUNG, Koji TAKEUCHI, Susumu OKABE, \\ Teizo MURATA and Keijiro TAKAGI \\ Department of Chemical Pharmacology, Faculty of Pharmaceutical Sciences, \\ University of Tokyo, Tokyo 113, Japan
}

Accepted August 4, 1976

\begin{abstract}
Effects of L-glutamine on acetylsalicylic acid (ASA)-induced gastric mucosal lesions were studied in mongrel dogs. It was confirmed that when oral ASA at 1.0 or $2.0 \mathrm{~g}$ per dog is given in two divided doses, there is severe and consistent dose-dependent mucosal damage in the glandular portion of the stomach in fasted dogs. However, when L-glutamine 2.0 or $4.0 \mathrm{~g}$ per dog in two divided doses is given concomitantly with ASA $2.0 \mathrm{~g}$ per dog orally, the gastric irritation is significantly inhibited. Instillation of $20 \mathrm{mM}$ of ASA in $100 \mathrm{mM} \mathrm{HCl}$ solution into the Heidenhain pouch of Beagle dogs produced a significant loss of $\mathrm{H}^{+}$from the pouch and a gain of $\mathrm{Na}^{+}$in the lumen compared with ASA-free controls. When L-glutamine $(100 \mathrm{mM})$ was given concomitantly with ASA (20mM) into the pouch, changes of electrolyte fluxes in response to ASA alone were significantly suppressed. However, $50 \mathrm{mM}$ of L-glutamine had no appreciable effect on acid back diffusion caused by ASA $20 \mathrm{mM}$. The amino acid itself had little effect on the ionic movement in the pouch. Gross bleeding from the pouch treated with ASA was never observed with the concomitant dosing of ASA and L-glutamine 50 or $100 \mathrm{mM}$.
\end{abstract}

We have already reported the marked inhibitory effect of L-glutamine on acetylsalicylic acid (ASA)-induced gastric irritation in normal, cirrhotic or pregnant rats, or in rats with a chronic gastric ulcer (1-4). It was experimentally determined that $\mathbf{L}$-glutamine produces a dose-dependent inhibition of acid back diffusion in response to ASA in the rat stomach (2-5). As dogs are frequently used in the study of gastric problems related to ASA (6-9), our present work was an attempt to determine the effects of L-glutamine in this species. This report contains data on the potent effect of this amino acid in preventing the noxious effect of ASA on the gastric mucosa in normal dogs and on the acid back diffusion in response to ASA in the stomach of Heidenhain pouch Beagle dogs.

\section{MATERIALS AND METHODS}

ASA-lesion formation: Thirty-six male mongrel dogs, weighing 8-10 kg, were deprived of food but allowed free access to water from 10:00 a.m. until the end of the experiments. ASA packed in a gelatin capsule was given orally to the dogs in the dose of $0.25,0.5$ or $1.0 \mathrm{~g}$ per dog at 6:00 p.m. of the same day. At 10:00 a.m. the next day, ASA in the same dose was given to these same dogs, i.e., the total dose of ASA was $0.5,1.0$ or $2.0 \mathrm{~g}$ per dog per day. An overdose of sodium pentobarbital was given i.v. at 6:00 p.m. of the same day after the 
dogs had fasted from food for a total of $32 \mathrm{hr}$. The stomach of each dog was removed, inflated by pouring in one liter of $1 \%$ formalin solution for $10 \mathrm{~min}$, then incised along the greater curvature and examined for lesions which had developed in the glandular portion. The length of each lesion was measured, summed and arbitrarily divided into 7 degrees as a lesion index as follows.

Total length of each lesion $(\mathrm{mm})$

Lesion index

$1-100, \quad 101-200,201-$

$01-300, \quad 301-400$

$401-500,501-600,600<$

The gastric specimens were put into Bouin solution for histological study. To determine the effect of L-glutamine on ASA-induced gastric lesions, L-glutamine at $0.5,1.0$ or $2.0 \mathrm{~g}$ per dog was mixed well with ASA at $1.0 \mathrm{~g}$ per dog, packed in a gelatin capsule and then given orally to the dogs, twice at a $16 \mathrm{hr}$ interval. As a control, lactose at $1.0 \mathrm{~g}$ per dog was mixed with ASA $1.0 \mathrm{~g}$ per dog and also given twice at the same interval.

Acid back diffusion: The methods used in this study were much the same as those employed by Davenport (8) or Chvasta and Cooke (9). Studies were done on 5 unanesthetized Beagle dogs ( 3 males and 2 femalcs) over a 4 month period. Each dog had a separate denervated (Heidenhain) pouch of the oxyntic glandular area of the stomach which drained via a stainless steel cannula with a 3 way stopcock. Water was provided for $18 \mathrm{hr}$ prior to the test. Studies were done twice a week only and never on consecutive days. Prior to testing, each dog was given atropine sulfate $(0.015 \mathrm{mg} / \mathrm{kg})$ i.m. to ensure basal secretion. At the beginning of each experiment, the pouch was rinsed thoroughly with a solution of $100 \mathrm{mM} \mathrm{HCl}$ and $54 \mathrm{mM} \mathrm{NaCl}$ and drained with a syringe. Forty $\mathrm{ml}$ of a solution of $100 \mathrm{mM} \mathrm{HCl}$ and $54 \mathrm{mM} \mathrm{NaCl}$ with phenol red (40 $\mathrm{mg} /$ liter) were injected into the pouch using a calibrated syringe. The contents were mixed for $30 \mathrm{sec}$ and a $5 \mathrm{ml}$ sample (initial sample) was removed for analysis. The contents of the pouch were mixed at 10 min intervals using a syringe connected to the 3 way stopcock. At the end of $30 \mathrm{~min}$, the pouch was emptied as completely as possible by gentle aspiration with a syringe, and the volume of fluid recovered (final sample) was measured. The residual volume, the volume of fluid remaining in the pouch after recovery of the injected solution, was calculated by dilution of the phenol red. The pouch was then rinsed twice with $154 \mathrm{mM} \mathrm{NaCl}$ and twice with the solution without phenol red which was to be used in the next period.

Each experiment consisted of 5 consecutive $30 \mathrm{~min}$ observation periods. Period 1 was the control; in period 2, ASA, ASA-1-glutamine, or L-glutamine alone was instilled, and in periods 3 to 5 the same solution as used in period 1 was tested. During period 2, the drug was instilled in an acid solution consisting of $100 \mathrm{mM} \mathrm{HCl}, 54 \mathrm{~m} \mathrm{M} \mathrm{NaCl}$ and phenol red $40 \mathrm{mg} /$ liter $(\mathrm{pH} \mathrm{1.1)}$. The residual volume of the pouch was determined for each test period and for the 5 dogs (mean \pm S.E.) was $2.95 \pm 0.22 \mathrm{ml}, 2.50 \pm 0.19 \mathrm{ml}, 2.15 \pm 0.20 \mathrm{ml}$, or $2.17 \pm 0.20 \mathrm{ml}$; the number of experiments was over 40 .

The initial and final samples were analyzed for titratable acidity, $\mathrm{Na}^{+}, \mathrm{K}^{+}$and phenol red concentrations. The acidity was measured by titrating a $1 \mathrm{ml}$ sample of the gastric con- 
tents with $0.1 \mathrm{~N} \mathrm{NaOH}$ to $\mathrm{pH} 7.0$ using an autonatic buret (Radiometer). The concentrations of $\mathrm{Na}^{+}$and $\mathrm{K}^{+}$were measured by a flame photometer (Hitachi). Phenol red concentration was measured by the method of Hunt and Knox (10). Osmolarity was measured using an Advanced Wide-Range Osmometer (Advanced Instruments). The ionic fluxes were calculated as the difference between the product of the final volume and concentration, and the product of the initial volume and concentration. Positive values indicate that the net flux was from mucosa to lumen while negative values indicate that the net flux was from lumen to mucosa.

Test solutions: The solution of ASA $(20 \mathrm{mM})$, ASA $(20 \mathrm{mM})+\mathrm{L}-\mathrm{glutamine}(50$ or $100 \mathrm{mM}$ ) or L-glutamine $(100 \mathrm{mM})$ alone was prepared by mixing each substance with $200 \mathrm{ml}$ of distilled water for $1 \mathrm{hr}$ in a $250 \mathrm{ml}$ of volumetric flask. The solution was made acid $(\mathrm{pH}$ 1.1 ) by adding conc. $\mathrm{HCl}$ solution (approx. $2.1 \mathrm{ml}$ ) to form $100 \mathrm{mM} \mathrm{HCl}$ solution, $54 \mathrm{mM}$ of $\mathrm{NaCl}$ solution and $10 \mathrm{mg}$ of phenol red and a final volume of $250 \mathrm{ml}$ was accomplished using distilled water. The solutions were prepared daily and mixed thoroughly before instillation in the pouch.

Statistics: Student's $t$-test was employed to determine the statistical significance of both lesion index and difference of ionic flux.

\section{RESULTS}

Effects of $\mathrm{L}$-glutamine on gastric lesions induced with ASA

ASA, when given at $0.5 \mathrm{~g}$ per dog per day in two divided doses, induced no detectable injuries to the gastric mucosa in 2 fasted dogs. However, the dosing of $1 \mathrm{~g}$ of ASA per dog per day resulted in an apparent development of mucosal erosions cither punctate or elongated, mainly in the oxyntic glandular area including the so-called "magenstrasse" and partly in the antrum. ASA at $2 \mathrm{~g}$ per dog per day induced much more severe and consistent irritation of gastric mucosa than that seen at $1 \mathrm{~g}$ per dog per day (Table 1). Histologically, the damage proved to be superficial erosions and there was never penetration beyond the muscularis mucosa. L-glutamine, given together with ASA at 2 g per dog per day, produced a definite inhibition of ASA-induced gastric lesions in dogs, i.e., the inhibition rate was $25.5 \%$, $43.1 \%$ or $62.7 \%$ at the dose of $1.0,2.0$ or $4.0 \mathrm{~g}$ per dog per day, respectively. The protective

TABLE 1. Effect of L-glutamine on ASA-induced gastric lesions in dogs

\begin{tabular}{lccccc}
\hline Treatment & $\begin{array}{c}\text { Dose } \\
\text { (g per dog } \\
\text { per day) }\end{array}$ & $\begin{array}{c}\text { No. of } \\
\text { dogs }\end{array}$ & $\begin{array}{c}\text { ASA lesions } \\
\text { Lesion index } \\
\text { (mean I S.E.) }\end{array}$ & $\%$ inhibition & P value \\
ASA & 0.5 & 2 & 0 & & \\
ASA & 1.0 & 2 & 1.5 & & \\
ASA-lactose & $2.0 \div 2.0$ & 8 & $5.1=0.5$ & & \\
ASA : L-glutamine & $2.0-1.0$ & 8 & $3.8 \div 0.9$ & 25.5 & N.S. \\
ASA + I-glutamine & $2.0+2.0$ & 8 & $2.9=0.5$ & 43.1 & $<0.01$ \\
ASA + L-glutamine & $2.0+4.0$ & 8 & $1.9 \div 0.4$ & 62.7 & $<0.001$ \\
\hline
\end{tabular}

ASA, ASA + L-glutamine, or ASA + lactose was given orally in two divided doses. (Student's $t$-test) 

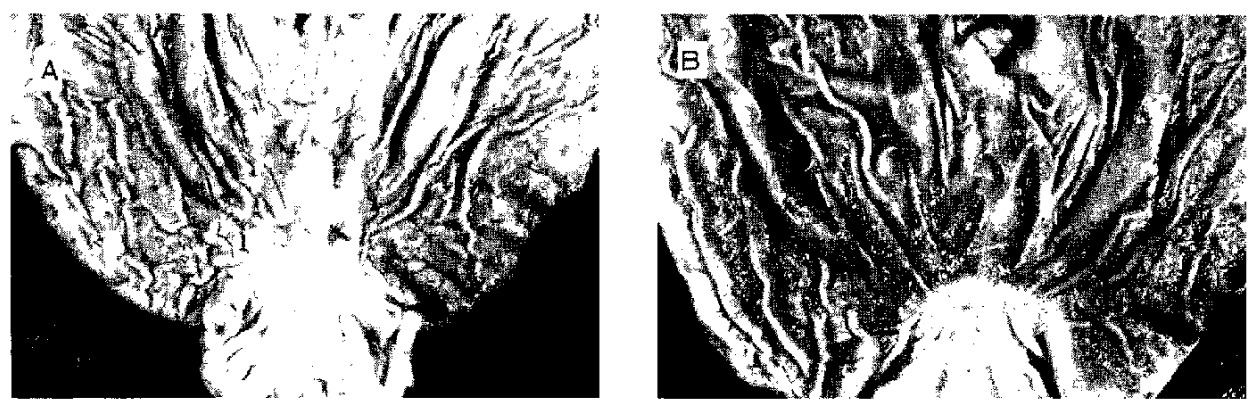

Fig. 1. Gross appearance of gastric lesions induccd by oral aceiylsalicylic acid (ASA: $2 \mathrm{~g} / \operatorname{dog})(\mathrm{A})$ and ASA $(2 \mathrm{~g} / \mathrm{dog})$ plus L-glutamine $(2 \mathrm{~g} / \mathrm{dog})(\mathrm{B})$. Note that ASAinduced lesions were almost completely inhibited by L-glutamine given concomitantly.

effect of L-glutamine against ASA lesions is illustrated in Fig. 1.

\section{Effects of L-glutamine on electrolyte fuxes induced by ASA}

Details of the net ionic fluxes are given in Table 2. Gastric instillation of $20 \mathrm{mM}$ of ASA at a $\mathrm{pH}$ of 1.1 produced a significant loss of $\mathbf{H}^{+}$from the lumen and gain of $\mathrm{Na}^{+}$into the lumen of Heidenhain pouch of dogs at periods 2 or 3 compared with the control period 1. The net $\mathrm{K}^{+}$flux into the lumen significantly increased at period 2. However, the changes of $\mathrm{H}^{+}$and $\mathrm{K}^{+}$fluxes in response to ASA tended to recover to the control level (period 1) by period 5, whereas the increased flux of $\mathrm{Na}^{+}$recovered almost completely by period 5 . Gross bleeding from the pouch was observed in all studies with ASA; this commenced during period 3 and continued in periods 4 and 5. ASA $20 \mathrm{mM}$, given together with $50 \mathrm{mM}$ of L-glutamine, also produced a significant loss of $\mathrm{H}^{+}$and $\mathrm{Na}^{+}$at periods 2 and 3 , the degree of which was almost the same as seen with ASA alone. When $100 \mathrm{mM}$ of $\mathrm{L}$-glutamine with $20 \mathrm{mM}$ of ASA was instilled into the pouch, the substantial clectrolyte changes between period 1 and periods 2 or 3 were considerably less compared to those of ASA alone. Actually in cases of ASA alone, the mean $\doteq$ S.E. of net difference of $\mathrm{H}^{+}$and $\mathrm{Na}^{+}$fluxes between periods 1 and 3 was $-428.2 \pm 5.1$ and $208.0 \div 60.5$, respectively. In contrast, in cases of ASA +Lglutamine $100 \mathrm{mM}$, the net difference of $\mathrm{H}^{+}$and $\mathrm{Na}^{+}$was $-13.1 \ldots 31.3$ and $23.1 \pm 38.2$, respectively. These values between ASA alone and ASA L-glutamine $100 \mathrm{mM}$ were significantly different $\left(\mathrm{H}^{+}: \mathrm{P}<0.001\right.$ and $\left.\mathrm{Na}^{+}: \mathbf{P}<0.05\right)$. L-glutamine at $100 \mathrm{mM}$ produced little alteration of ionic fluxes in the pouch compared with control period 1 except the significant reduction of $\mathrm{Na}^{+}$flux in period 2. It should be noted that ASA-induced bleeding from the pouch was almost completely prevented as the result of concomitant administration of ASA and L-glutamine at either 50 or $100 \mathrm{mM}$.

\section{DISCUSSION}

These studies provide further data that oral ASA produces gastric mucosal damage in fasted dogs $(6,7)$. The incidence of ASA-induced gastric lesions reported herein was $100 \%$ and the severity of lesions was quite consistent in each animal. As in our previous work 


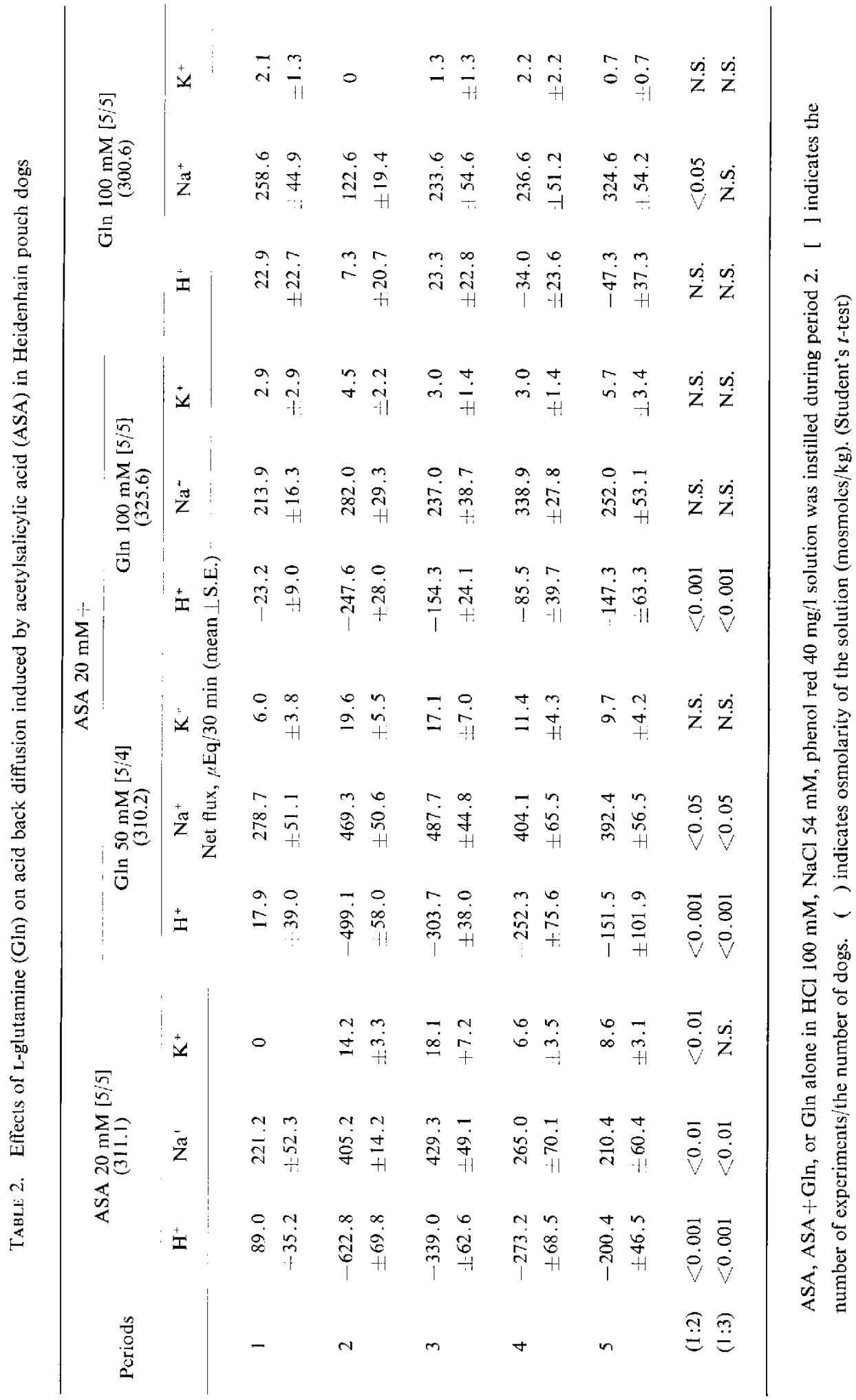


done in rats, L-glutamine, given together with ASA, produced a marked dose-dependent protection of the gastric mucosa against the irritative effects of ASA. The dose of L-glutamine which inhibited ASA gastric lesions by about $40-60 \%$ was equivalent or only double that of ASA.

Many substances, including ASA, are known to break down the gastric mucosal barrier and permit back diffusion of acid through the disrupted mucosa, resulting in gastric mucosal damage (11). To our knowledge, only one substance, carbenoxolone $\mathrm{Na}$, was found to inhibit acid back diffusion induced by human bile through the Heidenhain pouch of dogs, even though the drug did not affect the fux of $\mathrm{Na}^{+}(12)$. In contrast to the data observed in dogs, carbenoxolone $\mathrm{Na}$ was not reported to exert any appreciable effect on acid back diffusion induced by intragastric instillation of taurocholic acid in man (13).

We have already reported data that I-glutamine inhibits the back diffusion of $\mathrm{H}^{+}$and the flux of $\mathrm{Na}^{+}$induced by ASA in rats, as well as ASA-induced lesions (5). The inhibitory effect of $100 \mathrm{mM}$ of L-glutamine on acid back diffusion induced by $20 \mathrm{mM}$ of ASA was demonstrated herein by using a standard method of Heidenhain pouch in dogs. Unlike the effect of carbenoxolone $\mathrm{Na}$, L-glutamine also significantly inhibited the increment of $\mathrm{Na}-$ ions in the test solution in response to ASA. Although the osmolarity of the solution which contained $100 \mathrm{mM}$ L-glutamine and $20 \mathrm{mM}$ ASA was slightly higher (14.5 mosmoles/ $\mathrm{kg}$ in net difference) than that of ASA alone, the difference would hardly contribute to the effect of L-glutamine on acid back diffusion observed in the present study. The addition of certain amounts of mannitol to the $20 \mathrm{mM}$ ASA solution increased the osmolarity of the solution to approx. 325.6 mosmoles $\mathrm{kg}$, but had no notable influence on acid back diffusion. Reduction of the dose of I-glutamine, i.e., $50 \mathrm{mM}$, exerted no inhibition on $\mathrm{H}^{+}$and $\mathrm{Na}^{+}$ fluxes due to ASA. L-glutamine itself had little influence on ionic fluxes in Heidenhain pouch dogs. An explanation is now being sought for the significant reduction of $\mathrm{Na}^{+}$flux in period 2 in response to L-glutamine.

Davenport (14) and Chvasta and Cooke (9) found that when a Heidenhain pouch of dogs was irrigated with $20 \mathrm{mM}$ of $\mathrm{ASA}$ in a $100 \mathrm{mM} \mathrm{HCl}$ solution, the recovered fluid frequently contained blood, indicating a severe mucosal damage by the agent. We also found blood in the fluids recovered in periods 3, 4 and 5 after the ASA treatment. Lglutamine given concomitantly with ASA at the dose level of 50 or $100 \mathrm{mM}$ solution completely prevented this bleeding from the pouch. Therefore, this amino acid may to some extent inhibit ASA-induced gastric bleeding by a mechanism other than prevention of acid back diffusion, since the dose of $50 \mathrm{mM}$ of L-glutamine did not result in any significant inhibition of acid back diffusion in response to ASA in acid solution.

In rats, the absorption of ASA from either the gastric mucosa or gastroduodenal mucosa and the resulting pharmacologic effects, such as the analgesic, antipyretic or anti-inflammatory effects, remained unchanged in the presence of L-glutamine (15). We found in preliminary work that the absorption of ASA from Heidenhain pouch of dogs was not affected by the presence of L-glutamine in a dose which inhibited the back diffusion of acid and gastric bleeding in response to ASA. Thus, the therapeutic effect of ASA is apparently 
not influenced by a concomitant dosing of L-glutamine. Data from clinical studies on the concomitant administration of ASA and L-glutamine to patients with rheumatic diseases will be reported in a succeeding paper.

\section{REFERENCES}

1) Okabe, S., Takeuchi, K., Nakamura, K. And Takagi, K. Japan. J. Pharmacol. 24, 363 (1974)

2) Okabe, S., Takeuchi, K., Nakamura, K. and Takagi, K.: J. Pharm. Pharmacol. 26, 605 (1974)

3) Okabe, S., Takeuchi, K., Urushidani, T., Naganuma, T. and Takagi, K.: Japan. J. Pharmacol. 25, 687 (1975)

4) TAKeUchi, K., OKabe, S. AND Takagi, K.: Japan. J. Pharmacol. 26, 267 (1976)

5) Okabe, S., Honda, K., Takeuchi, K. And Takagi, K. : Am. J. dig. Dis. 20, 626 (1975)

6) Hurley, J.W. And Crandall, L.A.: Gastroenterology 46, 36 (1964)

7) LeV, R., Siegel, H.I. and Glass, G.B.J.: Gastroenterology 62, 970 (1972)

8) Davenport, H.W.: Gastroenterology 46, 245 (1964)

9) Chvasta, T.E. AND CoOKe, A.R.: J. Lab. clin. Med. 79, 302 (1972)

10) Hunt, J.N. And Knox, M.T.: J. Physiol. 163, 34 (1962)

11) Davenport, H.W.: Progress in Gastroenterology, Edited by Glass, G.B.J., p. 42, Grune \& Stratton, New York (1970)

12) CRoss, S. AND Rhodes, J.: Gastroenterology 62, 737 (1972)

13) IveY, K.J. AND GRAY, C.: Gastroenterology 64, 1101 (1973)

14) DaVenPort, H.W.: New Engl. J. Med. 276, 1307 (1967)

15) Tanaka, H., Kiyohira, A., Orimoto, H., Suzuki, Y., Takagi, K. and OKabe, S.: Japan. J. Pharmacol. 24, 903 (1974) 